\title{
Gross Total Resection of Chordoid Glioma of the Third Ventricle via Anterior Interhemispheric Transcallosal Transforaminal Approach at Two Stages
}

\author{
Ihsan Dogan ${ }^{1}$ Melih Ucer ${ }^{1}$ Mustafa Kemal Başkaya ${ }^{1}$ \\ ${ }^{1}$ Department of Neurological Surgery, University of Wisconsin School \\ of Medicine and Public Health, Madison, Wisconsin, United States \\ J Neurol Surg B 2018;00:S281-S282. \\ Address for correspondence Mustafa Kemal Başkaya, MD, \\ Department of Neurological Surgery, University of Wisconsin School \\ of Medicine and Public Health, 600 Highland Avenue, K4/8 CSC, \\ Box 8660, Madison, WI 53792, United States \\ (e-mail: baskaya@neurosurgery.wisc.edu).
}

\section{Abstract \\ Keywords \\ - suprasellar tumor \\ - interhemispheric transcallosal approach \\ - third ventricle tumor \\ - chordoid glioma}

Suprasellar tumors in particular tumors located in the retrochiasmatic area and anterior third ventricle are challenging cases in terms of optimal surgical exposure. Several approaches have been described including transsylvian, translamina terminalis, endoscopic endonasal, and anterior interhemispheric. Each approach has advantages and disadvantages. In this video, we present a case of retrochiasmatic anterior third ventricular tumor that was operated via anterior interhemispheric transcallosal transforaminal approach. The patient is a 42-year-old female who presented with sudden onset of severe headache and depressed level of consciousness. Computed tomography (CT) scan of the head showed a hemorrhage in the third ventricle and suprasellar cisterns. CT angiogram and magnetic resonance imaging (MRI) confirmed diagnosis of hemorrhagic mass lesion in the third ventricle. Upon further questioning of her family, we found out that she was having excessive urination and short-term memory problems for last 2 weeks. First, ventriculostomy was placed for obstructive hydrocephalus. She then underwent surgical resection via anterior interhemispheric transcallosal transforaminal approach. Foramen of Monro was enlarged by performing transchoroidal dissection. Using transforaminal route, tumor was resected. Due to the narrow surgical corridor and high vascularity of the tumor, decision was made to come back at a second stage. Using same surgical approach, in the second stage, gross total

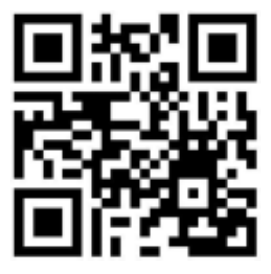

www.thieme.com/skullbasevideos

www.thieme.com/jnlsbvideos

received

October 17, 2017

accepted

December 3, 2017

published online

February 16, 2018
DOI https://doi.org/

10.1055/s-0038-1625967.

ISSN 2193-6331. (c) 2018 Georg Thieme Verlag KG

Stuttgart · New York
License terms

(ㄷ) (i) $\ominus$ (\$) 
resection was performed. Postoperative MRI confirmed gross total resection. Histopathology was chordoid glioma of the third ventricle. She made excellent recovery with persistent diabetes insipidus. Currently, she is completing radiation therapy. In this video, we demonstrate techniques and pitfalls of anterior interhemispheric transcallosal approach to anterior third ventricular tumor.

The link to the video can be found at: https://youtu.be/CI5c6Zup8sY.

Conflict of Interest

None. 